Reseña bibliográfica

\title{
Ciencias de la conducta y criminología forense en el Sistema Acusatorio
}

\author{
Eric García-López*
}

\author{
Garrido, V. (2018). La Criminología Forense y el Informe \\ Criminológico. Ciudad de México: Tirant lo Blanch.
}

En los ámbitos jurídicos suelen encontrarse menciones a casos, sentencias y estándares del sistema de justicia estadounidense, y es frecuente escuchar voces que aluden al estándar Daubert -remplazo mayoritario del estándar Frye- o al caso Kumho, entre muchos otros. Incluso, algunos juristas iberoamericanos mencionan la Regla 702 de las llamadas "Federal Rules of Evidence". En conjunto, estos criterios tienen una notable influencia forense, puesto que implican la valoración de la prueba científica ante los tribunales de justicia. Asimismo, no son pocas las menciones a casos y sentencias de las cortes de justicia en Estados Unidos en las que se ha subrayado la importancia del estudio científico del comportamiento humano, como sucede, solo por mencionar dos ejemplos, en la sentencia Jenkins y en el caso Roper vs. Simmons.

En la sentencia Jenkins -que data de 1962-quedó establecido que tanto psicólogos como psiquiatras están facultados para emitir un diagnóstico -en ese caso, sobre esquizofrenia-y presentar sus conclusiones ante los tribunales de justicia. Y en Roper vs. Simmons -caso que ocurrió en 1994-, la Corte Suprema estadounidense requirió el auxilio de la American Psychological Association (APA) - en el año 2005- para que aportara información valiosa sobre la inmadurez neurobiológica y cognitiva del cerebro adolescente; y con base en dichos estudios psicológico-neurocientíficos, la Corte finalmente fundamentó la inconstitucionalidad de imponer la pena de muerte a los adolescentes que cometan algún delito grave.

Estos dos casos, entre muchos otros, afirman la importancia del estudio del cerebro y el comportamiento humano, así como su influencia decisiva en el sistema jurídico; sin embargo, resulta vergonzoso que hoy en día haya todavía quien desconozca esta añeja equivocación: pretender que la psicología es menos científica que la psiquiatría, y aceptarlo así muestra no solo una amplia banalidad, sino una rotunda ignorancia. En especial, porque ello vulnera las contribuciones mutuas que actualmente confluyen en el Neuroderecho, la Criminología y la Psicopatología Forense, conceptos y aplicaciones de ordenada amalgama que contribuyen a la Justicia.

En efecto, uno de los objetivos de nuestras disciplinas es contribuir a la Justicia, y es por esto que es tan bien recibido un libro como el que ha coordinado el profesor Vicente Garrido Genovés, y cuya edición mexicana ha estado a cargo de Luz Anyela Morales Quintero. Este libro constituye una rigurosa producción científica que en diecisiete capítulos aborda temas como "la prueba y su valoración en México: implicaciones para el quehacer criminológico", el "modelo del triple riesgo delictivo" -escrito con esa claridad que distingue a Santiago Redondo Illescas-, o "las decisiones del Tribunal Supremo y los conocimientos de la Criminología", solo por mencionar algunos.

Los lectores de esta obra no podrán evitar ninguno de los capítulos que estructuran "La criminología forense y el informe criminológico", ya que en cada uno de ellos encontrarán guías prácticas y planteamientos indispensables para comprender los nexos entre la jurisprudencia y la pericial criminológica, así como el análisis criminológico de la escena del crimen y la evaluación del abuso sexual infantil, entre muchos otros temas infranqueables para quienes dedican el ejercicio profesional a estos ámbitos tan oscuros, y para los cuales se requiere no solo una robusta formación académica, sino también la indispensable y mayor de las noblezas.

Noble, dice la RAE, es un adjetivo que implica ser preclaro, ilustre y generoso; y así es este libro, reflejo fiel de sus autoras/es, quienes han dedicado la vida a abrirle camino en Iberoamérica a disciplinas tan necesarias como la Psicología Jurídica y Forense, la Criminología y, en general, al estudio científico del comportamiento humano en todos los ámbitos jurídicos.

Esta obra ha sido publicada en México, en febrero de 2018; y en marzo del mismo año, la Facultad de Derecho

\footnotetext{
* Catedrático de victimología e investigador titular en el Instituto Nacional de Ciencias Penales. Doctor en Psicopatología Forense y periodo académico del Doctorado en Neurociencia por la Universidad Complutense de Madrid. garcialopez@gmx.com
} 
de la Benemérita Universidad Autónoma de Puebla y el Tribunal Superior de Justicia del mismo Estado, así como la Universidad de Guadalajara y el Instituto Nacional de Ciencias Penales, recibieron en sus respectivos recintos al profesor Garrido Genovés y a la profesora Morales Quintero. De ella ha de resaltarse la brillante revisión publicada en el capítulo 7, en donde alude a la sentencia Jenkins y añade, en prospectiva:

"[...] vale la pena analizar las oportunidades y los desafíos que representa la función de la Criminología dentro del Sistema Penal Acusatorio, en particular como ciencia forense y, específicamente, en lo que compete a los procesos de admisibilidad y valoración de su conocimiento en ese ámbito" (p. 275).

Asimismo, la autora señala con acierto que en México -en cuanto al quehacer forense en general- "[...] es muy probable que estemos como en Estados Unidos en los años 90s" (p. 276), más preocupados por la admisión del experto que por el sustento científico de sus aportaciones. A ello, desde luego, en nada contribuye la confusión terminológica que se observa en licenciaturas de reciente cuño, cuando era tan necesario fortalecer el posgrado, antes que importar traducciones erróneas.
Para concluir esta reseña, no puede dejarse de lado subrayar la importancia de la "valoración de la prueba criminológica forense para los operadores jurídicos", muestra inequívoca del diálogo indispensable entre togas negras y batas blancas. En dicho capítulo, el profesor Vicente Garrido llama la atención sobre los sesgos cognitivos inherentes al proceso judicial y plantea una valiosa guía práctica a modo de preguntas generales para la valoración de la prueba criminológica.

En síntesis, esta obra supera lo exigible en Daubert: es demostrable lo que en ella se explica, los fundamentos de cada capítulo están basados en publicaciones científicas de alto impacto, se analiza el margen de error de las disciplinas sociales y de la conducta, y la comunidad científica reconoce los contenidos como propios de un proceso riguroso de evaluación y selección.

Con este nuevo libro, los lectores tienen ante sí una obra imprescindible para dar respuesta a los tribunales de justicia y para conjugar con equilibrio al crimen y a sus actores, agresores y víctimas, siempre buscando la restauración del tejido social. 